\title{
Ultraviolet and Visible Photodetection using 3C-SiC/Si Hetero-epitaxial Junction
}

\author{
Abu Riduan Md Foisal ${ }^{1}$, Toan Dinh ${ }^{1}$, Philip Tanner ${ }^{1}$, Hoang-Phuong Phan ${ }^{1}$, Tuan- \\ Khoa Nguyen ${ }^{1}$, Alan Iacopi ${ }^{1}$, Erik W. Streed ${ }^{2,3}$ and Dzung Viet Dao ${ }^{1,4}$ \\ ${ }^{1}$ Queensland Micro-Nanotechnology Centre, ${ }^{2}$ Centre for Quantum Dynamics, Griffith Universi- \\ ty, Brisbane, Queensland, Australia 4111 \\ ${ }^{3}$ Institute of Glycomics, ${ }^{4}$ School of Engineering, Griffith University, Southport, Gold Coast, \\ Australia 4222 \\ ar.mdfoisalegriffithuni.edu.au
}

\begin{abstract}
This paper demonstrates the prospect of using a 3C-SiC/Si heterostructure as an ultraviolet and visible photodetector. The heterojunction has been grown epitaxially on Si-substrate via a Low Pressure Chemical Vapor Deposition technique at $1000{ }^{\circ} \mathrm{C}$. The detector shows a good diode characteristic with a rectification ratio of $1.03 \times 10^{3}$ and a reverse leakage current of $7.2 \times 10^{-6}$ $\mathrm{A}$ at $2 \mathrm{~V}$ in dark conditions. The responsivity of the device is found to be $5.4 \times 10^{-2} \mathrm{~A} / \mathrm{W}$ and $3.18 \times 10^{-2} \mathrm{~A} / \mathrm{W}$ at a reverse bias of $2 \mathrm{~V}$ under visible $(635$ $\mathrm{nm})$ and $\mathrm{UV}(375 \mathrm{~nm})$ illumination, respectively. An energy band diagram is proposed to explain the photosensitivity of the heterostructure.
\end{abstract}

Keywords: 3C-SiC/Si heterojunction, Responsivity, UV-visible light, Band diagram.

\section{Introduction}

The photodetectors, which are consisted of only one semiconductor material (such as $\mathrm{ZnO}, \mathrm{GaN}$, and $\mathrm{Si}$ ), absorb the photons which have higher energy than the bandgap of that material. This property limits their applications in wide spectral sensitivity devices, such as- multispectral image sensors and switches [1]-[2]. A number of studies also have reported on wide band photodetectors based on MSM, p-n and p-i-n junction, and metal schottky structure [3]-[4].

Recently, heterojunction based ultraviolet (UV)-visible photodetectors using different materials, for instance, $\mathrm{n}-\mathrm{ZnO} / \mathrm{p}-\mathrm{Si}$ [4], $\mathrm{ZnO}-\mathrm{CdS}$ [1], $\mathrm{Cu}_{2} \mathrm{O} / \mathrm{ZnO}$ [5], and a$\mathrm{SiC} / \mathrm{a}-\mathrm{Si}$ [6], have drawn considerable attention. In heterostructure devices, the top wide band semiconductor layer works as a window for low energy photons, which will be then absorbed in the bottom low band gap material.

In addition, Silicon carbide ( $\mathrm{SiC}$ ) is one of the most promising wide bandgap materials due to its excellent chemical stability, as well as its mechanical and electrical properties [7]-[9]. Among 200 polytypes of $\mathrm{SiC}$, only 3C-SiC can be grown epitaxially on a large $\mathrm{Si}$-wafer at around $1000^{\circ} \mathrm{C}$. As a result, the cost of the wafer reduces 
significantly [10]. Hence, the 3C-SiC on $\mathrm{Si}$ structure has been used for a number of N/MEMS applications, for instance, temperature sensors [11]-[12], piezoresistive sensors [13]-[15], and pressure sensors [16]-[17].

However, due to different thermal expansion coefficients and the lattice mismatch between $3 \mathrm{C}-\mathrm{SiC}$ and $\mathrm{Si}$, the grown $3 \mathrm{C}-\mathrm{SiC} / \mathrm{Si}$ heterojunction experiences crystal defects and film stress at the interface [18]-[19]. The stacking faults, as well as film quality, can be improved by carbonizing the activated silicon surface before the growth of 3C-SiC [20]-[21]. A number of studies have reported that, despite the presence of crystal defects at the interface, 3C-SiC/Si heterojunction shows excellent diode characteristics and stable electrical behavior [22]-[24]. Most of the $\mathrm{SiC}$ based photodetectors focus on detecting the UV light [25]-[26]. Therefore, in this study, we investigate the potentiality of detecting both ultraviolet and visible photons in the same 3C-SiC/Si heterostructure.

\section{Device Fabrication and Experimental details}

The 3C-SiC film is grown epitaxially on a $\mathrm{Si}(100)$ substrate using the LPCVD technique at $1000^{\circ} \mathrm{C}$. Prior to the epitaxial growth process, the Si-substrate was carbonized to ensure a void free $\mathrm{Si}$ under the SiC layer. After that, an Alternative Supply Epitaxy method is used to grow $3 \mathrm{C}-\mathrm{SiC}$ of desired thickness by using silane and propylene as precursors [27]-[28]. The 3C-SiC film is grown to a thickness of approximately $400 \mathrm{~nm}$ with a carrier concentration of $10^{16}-10^{17} \mathrm{~cm}^{-3}$.

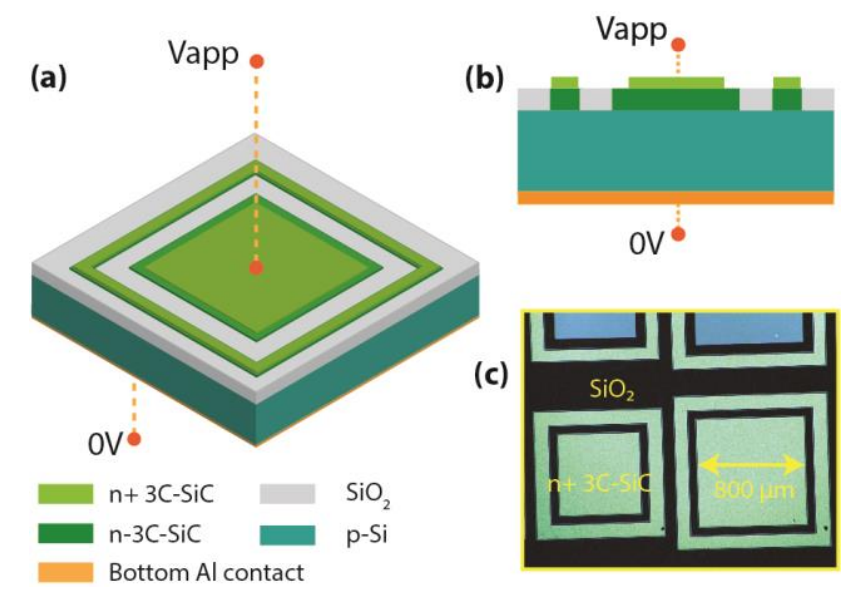

Fig. 1. (a) A schematic and (b) cross-section diagram of the proposed heterostructure; (c) the fabricated 3C-SiC/Si heterostructure.

In order to create isolated $3 \mathrm{C}-\mathrm{SiC} / \mathrm{Si}$ heterojunctions, the $3 \mathrm{C}-\mathrm{SiC}$ film is patterned by conventional lithography processes and then etched using plasma etching in a LAM 480 system. Following this, a $100 \mathrm{~nm}$ oxide layer is deposited on the film utiliz- 
ing a Hitech LPCVD furnace. Consequently, more than $90 \%$ of the oxide area is etched from the isolated $3 \mathrm{C}$-SiC top surface and then an n-type highly doped 3C-SiC layer is selectively deposited to make top contact. To form the back contact, the $3 \mathrm{C}$ $\mathrm{SiC}$ from the back surface is removed by inductively coupled plasma etching and then $\mathrm{Al}$ is sputtered as a back contact. The details of the device fabrication steps can be found elsewhere [29]. A schematic and a cross-sectional diagram of the proposed heterostructure are shown in Fig. 1(a) and (b), respectively. Fig. 1(c) represents a microscopic image of the fabricated devices with different sizes. The current-voltage characteristics of the heterostructure are measured by an Agilent U2722A source measuring unit. A $635 \mathrm{~nm}$ and a $375 \mathrm{~nm}$ (THORLAB) laser are employed for the photocurrent measurements.

\section{$3 \quad$ Results and Discussion}

The I-V characteristics of the $\mathrm{n}-3 \mathrm{C}-\mathrm{SiC} / \mathrm{p}-\mathrm{Si}$ heterojunction in dark conditions and under UV-visible illumination are exhibited in Fig. 2. As observed the heterojunction shows a good rectifying behavior with a rectification ratio $\left(\mathrm{I}_{\mathrm{F}} / \mathrm{I}_{\mathrm{R}}\right)$ of $1.03 \times 10^{3}$ at forward/reverse biases of $2 \mathrm{~V}$.

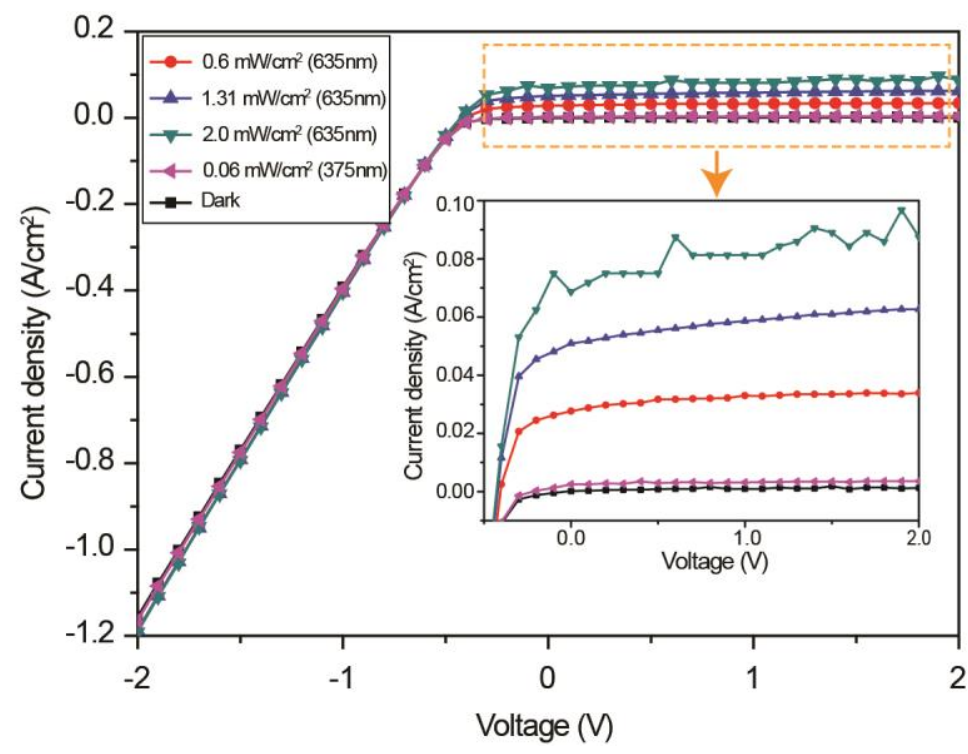

Fig. 2. Current-voltage characteristics of the $3 \mathrm{C}-\mathrm{SiC} / \mathrm{Si}$ heterojunction in dark conditions and under UV (375 nm) and visible $(635 \mathrm{~nm})$ light. (Inset shows the zoom-in-view of the IV characteristic in reverse bias conditions). 
The I-V characteristic in dark conditions can be modelled by the standard diode equation [30].

$$
J=J_{0}\left(\exp \left(\frac{q V_{a p p}}{n k T}\right)-1\right)
$$

where, $J_{0}$ is the reverse saturation current density, $q$ is the electric charge, $V_{a p p}$ is the applied voltage, $n$ is the diode ideality factor, $k$ is the Boltzman constant and $T$ is the temperature. The ideality factor of the forward bias current is found to be 1.25 , which indicates that the forward current dominates by a diffusion mechanism, but also it consists of a small portion of generation-recombination components. The generationrecombination may result from the $\mathrm{SiC} / \mathrm{Si}$ interface defects.

The photo I-V characteristics are measured under UV-visible illumination at different intensities as shown in Fig. 2. As observed, the influence of both visible (635 $\mathrm{nm})$ and UV (375 nm) light in forward bias current is almost insignificant. However, the current is affected significantly in reverse bias conditions. For instance, the photo current in reverse bias condition $(2 \mathrm{~V})$, at an illumination of $2 \mathrm{~W} / \mathrm{cm}^{2}$, increases by about 69 times as compared to that in forward bias at $-2 \mathrm{~V}$. Therefore, the photodetector is connected in reverse bias to measure the photo-sensitivity. The diode equation in optical environments can be written as-

$$
I=I_{0}\left(\exp \left(\frac{q V_{a p p}}{n k T}\right)-1\right)+I_{o p}
$$

where, $I_{o p}$ is the optical generation current.

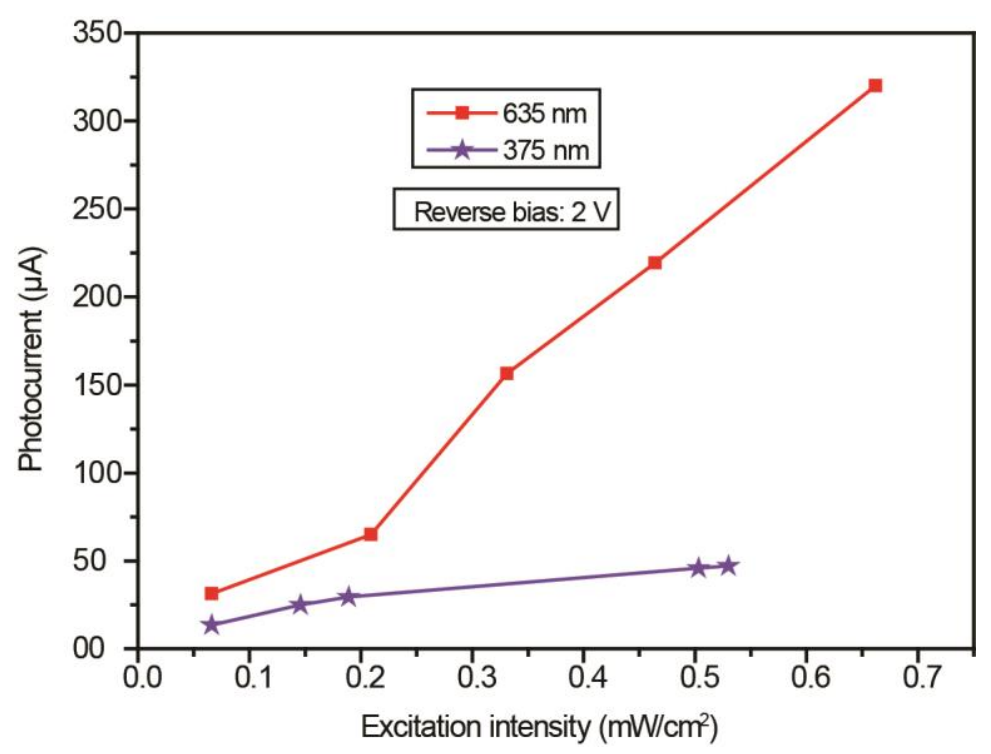

Fig. 3. Photocurrent of the heterostructure as a function of light intensity at a bias voltage of $2 \mathrm{~V}$. 
The intensity dependent photocurrents $\left(I_{p h}=I_{\text {photo }}-I_{\text {dark }}\right)$ under both UV and visible illumination are shown in Fig. 3. The photocurrent increases significantly under visible illumination compared to that in UV light. For example, the photocurrent in visible light is about 5 times higher than that in UV light at an illumination of $0.5 \mathrm{~W} / \mathrm{cm}^{2}$ and a reverse bias of $2 \mathrm{~V}$.

The mechanism behind the observed photocurrent characteristics at different light conditions can be explained on the basis of the energy band diagram (Fig. 4). The band offsets are obtained from [31]. The band diagram of the heterostructure in dark conditions at a reverse bias of $2 \mathrm{~V}$ is shown in Fig. 4(a). The width of the depletion region in $\mathrm{Si}$ will be greater than that in $3 \mathrm{C}$-SiC because of the lower ratio of the hole concentration in $\mathrm{p}-\mathrm{Si}$ to the electron concentration in the $\mathrm{n}-3 \mathrm{C}-\mathrm{SiC}$ side. As observed, the electrons tunnel from the valance band of Si to the trap states and are followed by a thermionic emission to the conduction band of $\mathrm{SiC}$ [32], resulting a small current flow in dark environments at reverse bias conditions.
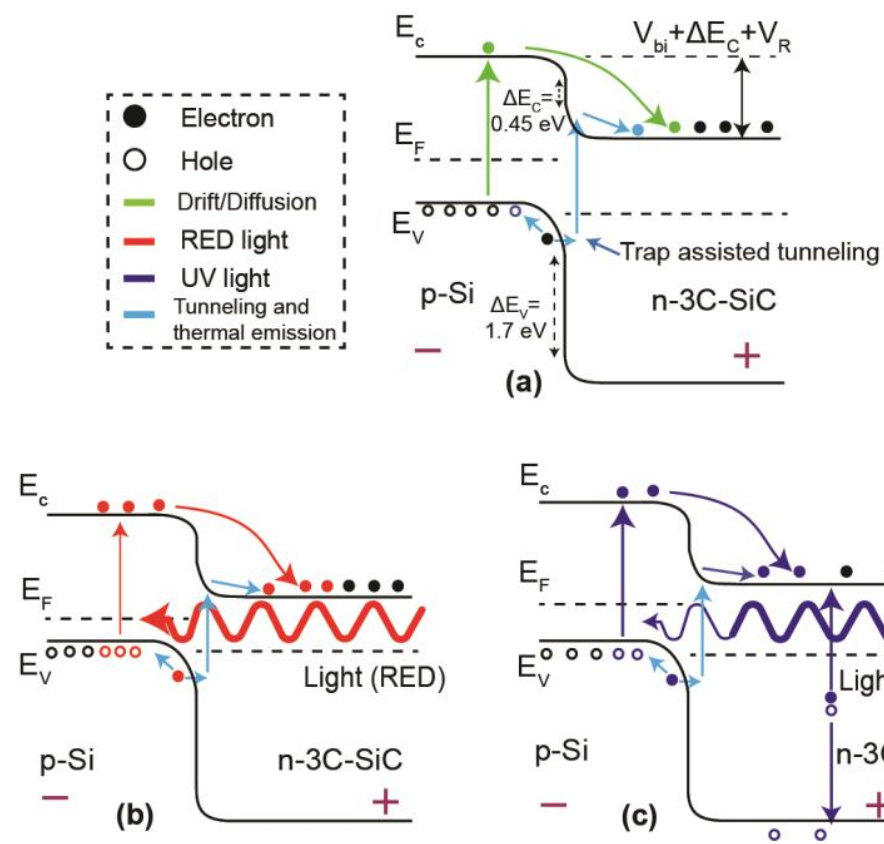

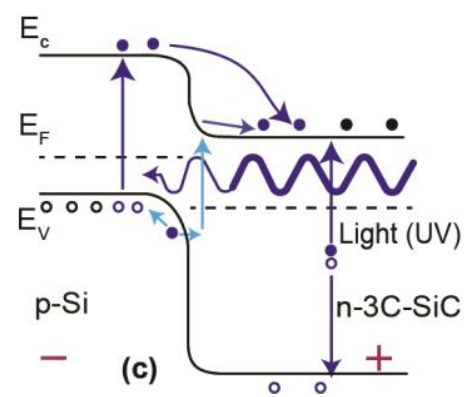

Fig. 4. Electron-hole pair generation and recombination at reverse bias in (a) dark condition, and under (b) visible light (635 nm) and (c) UV light (375 nm).

The photocurrent behavior under visible $(635 \mathrm{~nm})$ illumination can be explained by Fig. 4(b), where the light incidence comes from the top $3 \mathrm{C}-\mathrm{SiC}$ side. Due to the large bandgap of $3 \mathrm{C}-\mathrm{SiC}(2.38 \mathrm{eV})$, the visible light transmits through the $3 \mathrm{C}-\mathrm{SiC}$ layer and primarily absorbs in the $\mathrm{Si}$ layer, resulting in the photogeneration process of electron- 
hole pairs. In reverse bias conditions, the generated holes and electrons move towards the negative and positive terminal, respectively. As there is no barrier under the reverse bias conditions, the photogenerated carriers can easily move towards the opposite potential terminals and hence, the photocurrent increases significantly under visible illumination.

On the other hand, under UV (375 nm) light, the photons mainly absorb in 3C-SiC and some photons will reach the p-Si layer due to the thin $(400 \mathrm{~nm}) 3 \mathrm{C}-\mathrm{SiC}$ layer. As the incident photon energy $(3.32 \mathrm{eV})$ is much higher than the bandgap of $\mathrm{Si}(1.12 \mathrm{eV})$, under UV illumination the photoconversion efficiency of Si is very low and extra photon energies will be lost as heat within the device [30],[33]. However, the photogenerated electron and hole in $3 \mathrm{C}-\mathrm{SiC}$ will move towards the positive and negative bias, respectively. As a result of a low carrier generation under UV illumination, a higher photocurrent under visible illumination is observed than that in UV light.

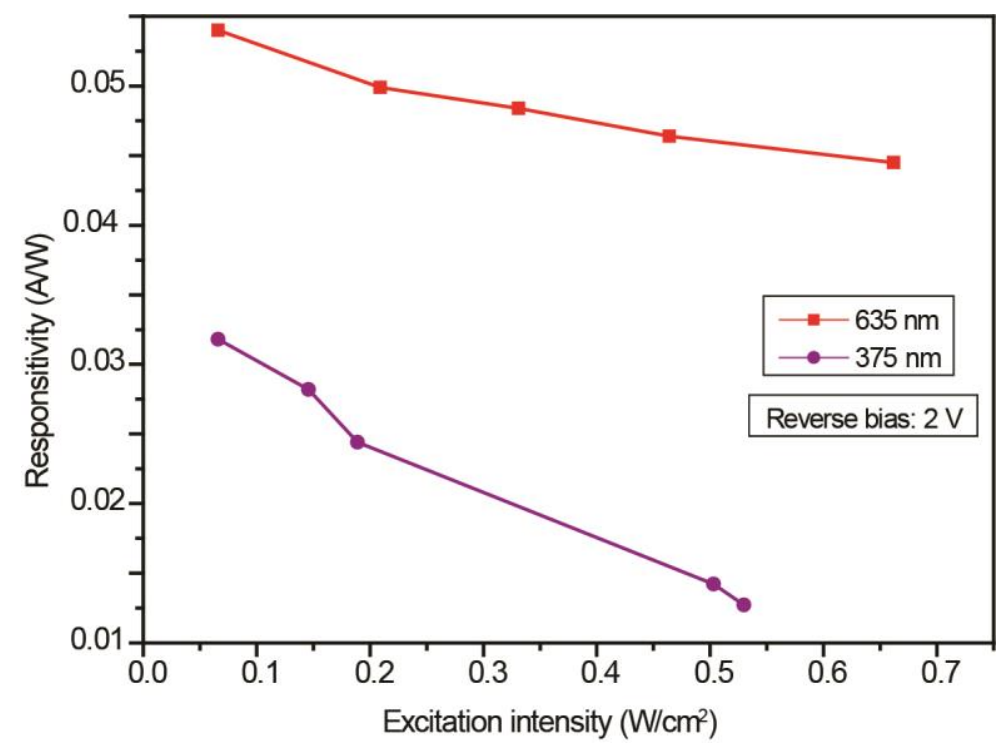

Fig. 5. Derived the photon responsivity under UV and visible illuminations relative to the excitation intensity.

The responsivity, as a function of intensity, of the heterostructure as shown in Fig. 5 can be defined as [34]-

$$
\mathcal{R}=\frac{I_{p h}}{P_{i}}=\frac{I_{p h}}{I_{i} \times A}
$$

where, $I_{p h}$ is the photocurrent, $I_{i}$ is the illumination intensity, and $A$ is the device area. The heterostructure shows a peak responsivity of $5.4 \times 10^{-2} \mathrm{~A} / \mathrm{W}$ and $3.2 \times 10^{-2} \mathrm{~A} / \mathrm{W}$ 
under the illumination of visible $(635 \mathrm{~nm})$ and UV $(375 \mathrm{~nm})$, respectively, at an intensity of $66 \mathrm{~mW} / \mathrm{cm}^{2}$ with a reverse bias of $2 \mathrm{~V}$. As observed, the photoresponse decreases with increasing intensity. This behavior is primarily ascribed to the carrier screening which reduces the internal electric field [35]-[36]. So, the velocity of the photogenerated carrier decreases and hence they recombine before being collected at the external electrical contacts [37].

\section{Conclusion}

In summary, an n-3C-SiC/p-Si-type heterojunction photodetector has been fabricated using a LPCVD technique and shows a rectification of $1.03 \times 10^{3}$. In addition, a peak responsivity of $5.4 \times 10^{-3} \mathrm{~A} / \mathrm{W}$ and $3.2 \times 10^{-3} \mathrm{~A} / \mathrm{W}$ at $2 \mathrm{~V}$ is observed under visible and UV illumination, respectively. The mechanism behind the different photosensitivity under UV and visible illumination are explained via the energy band diagrams. The results indicate the high potentiality using the same structure for detecting both UV and visible light. Further optimization of thickness of the $3 \mathrm{C}$-SiC film and the use of ultralow illumination intensity are expected to improve the performance of the $3 \mathrm{C}-\mathrm{SiC} / \mathrm{Si}$ heterojunction.

\section{References}

1. Zhang, F., Ding, Y., Zhang, Y., Zhang, X. Wang, Z.L.: Piezo-phototronic effect enhanced visible and ultraviolet photodetection using a $\mathrm{ZnO}-\mathrm{CdS}$ core-shell micro/nanowire. ACS Nano, 6(10), 9229-9236 (2012).

2. Fang, X., Bando, Y., Liao, M., Gautam, U.K., Zhi, C., Dierre, B., Liu, B., Zhai, T., Sekiguchi, T., Koide, Y. Golberg, D.: Single-crystalline ZnS nanobelts as ultraviolet-light sensors. Advanced Materials, 21(20), 2034-2039 (2009).

3. Ohta, H., Kamiya, M., Kamiya, T., Hirano, M., Hosono, H.: UV-detector based on pnheterojunction diode composed of transparent oxide semiconductors, $\mathrm{p}-\mathrm{NiO} / \mathrm{n}-\mathrm{ZnO}$. Thin Solid Films, 445(2), 317-321 (2003).

4. Mridha, S., Basak, D.: Ultraviolet and visible photoresponse properties of $\mathrm{n}-\mathrm{Zn} \mathrm{O} / \mathrm{p}-\mathrm{Si}$ heterojunction. Journal of Applied Physics, 101(8), 083102 (2007).

5. Elfadill, N. G., Hashim, M. R., Saron, K. M. A., Chahrour, K. M., Qaeed, M. A., Bououdina, M. Ultraviolet-visible photo-response of $\mathrm{p}-\mathrm{Cu} 2 \mathrm{O} / \mathrm{n}-\mathrm{ZnO}$ heterojunction prepared on flexible (PET) substrate. Materials Chemistry and Physics, 156, 54-60 (2015).

6. Fang, Y. K., Hwang, S. B., Chen, K. H., Liu, C. R., Tsai, M. J., Kuo, L. C.: An amorphous $\mathrm{SiC} / \mathrm{Si}$ heterojunction pin diode for low-noise and high-sensitivity UV detector. IEEE Transactions on Electron Devices, 39(2), 292-296 (1992).

7. Foisal, A. R. M., Qamar, A., Phan, H.-P., Dinh, T., Tuan, K. N., Tanner, P., Streed, E. W., Dao, D. V.: Pushing the Limits of Piezoresistive Effect by Optomechanical Coupling in 3C-SiC/Si Heterostructure. ACS applied materials \& interfaces, 9(46), 39921-39925 (2017). 
8. Nguyen, T.-K., Phan, H.-P., Dinh, T., Han, J., Dimitrijev, S., Tanner, P., Foisal, A. R. M., Zhu, Y., Nguyen, N.-T. Dao, D. V.: Experimental investigation of piezoresistive effect in p-type 4H-SiC. IEEE Electron Device Letters, 38(7), 955-958 (2017).

9. Nguyen, T.-K., Phan, H.-P., Han, J., Dinh, T., Foisal, A. R. M., Dimitrijev, S., Zhu, Y., Nguyen, N.-T. Dao, D. V.: Highly sensitive p-type 4H-SiC van der Pauw sensor. RSC Advances, 8(6), 3009-3013 (2018).

10. Qamar, A., Tanner, P., Dao, D. V., Phan, H.-P., Dinh, T.: Electrical properties of p-type 3C-SiC/Si heterojunction diode under mechanical stress. IEEE Electron Device Letters, 35(12), 1293-1295 (2014).

11. Phan, H.-P., Cheng, H. H., Dinh, T., Wood, B., Nguyen, T.-K., Mu, F., Kamble, H., Vadivelu, R., Walker, G., Hold, L, Iacopi, A. et al.: Single-Crystalline 3C-SiC anodically bonded onto glass: an excellent platform for high-temperature electronics and bioapplications. ACS applied materials \& interfaces, 9(33), 27365-27371 (2017).

12. Foisal, A. R. M., Phan, H.-P., Kozeki, T., Dinh, T., Tuan, K.-N., Qamar, A., Lobino, M., Namazu, T., Dao, D. V.: 3C-SiC on glass: an ideal platform for temperature sensors under visible light illumination. RSC Advances, 6(90), 87124-87127 (2016).

13. Phan, H.-P., Dinh, T., Kozeki, T., Nguyen, T.-K., Qamar, A., Namazu, T., Nguyen, N.-T. Dao, D. V., Nano strain-amplifier: Making ultra-sensitive piezoresistance in nanowires possible without the need of quantum and surface charge effects. Applied Physics Letters, 109(12), 123502 (2016).

14. Phan, H.-P., Dao, D. V., Tanner, P., Wang, L., Nguyen, N.-T., Zhu, Y., Dimitrijev, S.: Fundamental piezoresistive coefficients of p-type single crystalline 3C-SiC. Applied Physics Letters, 104(11), 111905 (2014).

15. Phan, H.-P., Dao, D. V., Wang, L., Dinh, T., Nguyen, N.-T., Qamar, A., Tanner, P., Dimitrijev, S. Zhu, Y.: The effect of strain on the electrical conductance of p-type nanocrystalline silicon carbide thin films. Journal of Materials Chemistry C, 3(6), 1172-1176 (2015).

16. Young, D. J., Du, J., Zorman, C. A. Ko, W. H.: High-temperature single-crystal 3C-SiC capacitive pressure sensor. IEEE Sensors Journal, 4(4), 464-470 (2004).

17. Phan, H.-P., Nguyen, T.-K., Dinh, T., Iacopi, A., Hold, L., Shiddiky, M. J., Dao, D. V., Nguyen, N.-T.: Robust free-standing nano-thin SiC membranes enable direct photolithography for MEMS sensing applications. Advanced Engineering Materials, 20(1) (2018).

18. Phan, H.-P., Dao, D. V., Tanner, P., Han, J., Nguyen, N.-T., Dimitrijev, S., Walker, G., Wang, L., Zhu, Y.: Thickness dependence of the piezoresistive effect in p-type single crystalline 3C-SiC nanothin films. Journal of Materials Chemistry C, 2(35), 7176-7179 (2014).

19. Massoubre, D., Wang, L., Hold, L., Fernandes, A., Chai, J., Dimitrijev, S., Iacopi, A.: Vertically conductive single-crystal SiC-based Bragg reflector grown on Si wafer. Scientific Reports, 5, 17026 (2015).

20. Nishino, S., Powell, J. A., Will, H. A.: Production of large-area single-crystal wafers of cubic SiC for semiconductor devices. Applied Physics Letters, 42(5), 460-462 (1983).

21. Anzalone, R., G. Litrico, N. Piluso, R. Reitano, A. Alberti, P. Fiorenza, S. Coffa, F. La Via.: Carbonization and transition layer effects on 3C-SiC film residual stress. Journal of Crystal Growth, 473, 11-19 (2017).

22. Chaudhry, M. I.: Electrical transport properties of crystalline silicon carbide/silicon heterojunctions. IEEE electron device letters, 12(12), 670-672 (1991).

23. Tanner, P., Dimitrijev, S., Harrison, H. B.: Current mechanisms in n-SiC/p-Si heterojunctions. Proc. of the 2008, Conf. on Optoelectronic and Microelectronic Mat. and Dev., 41 43, (2008).

24. Perzolt, J., Foster, C., Weih, P., Masri, P.: Electrical characterization of SiC/Si heterostructures with Ge-modified interfaces. Applied Surface Science, 184(1-4), 79-83, (2001). 
25. Monroy, E., Omnès, F., Calle, F.: Wide-bandgap semiconductor ultraviolet photodetectors. Semiconductor Science and Technology, 18(4), 33 (2003).

26. Morkoc, H., Strite, S., Gao, G. B., Lin, M. E., Sverdlov, B., Burns, M.: Large-band-gap SiC, III-V nitride, and II-VI ZnSe-based semiconductor device technologies. Journal of Applied Physics, 76(3), 1363-1398 (1994).

27. Wang, L., Dimitrijev, S., Han, J., Iacopi, F., Zou, J.: Transition between amorphous and crystalline phases of $\mathrm{SiC}$ deposited on Si substrate using $\mathrm{H}_{3} \mathrm{SiCH}_{3}$. Journal of Crystal Growth, 311, 4442-4446, (2009).

28. Dao, D. V., Phan, H.-P., Qamar, A., Dinh, T.: Piezoresistive effect of p-type single crystalline 3C-SiC on (111) plane. RSC Advances, 6(26), 21302-21307 (2016).

29. Tanner, P., Iacopi, A., Phan, H.-P., Dimitrijev, S., Hold, L., Chaik, K., Walker, G., Dao, D. V., Nguyen, N.T.: Excellent Rectifying Properties of the n-3C-SiC/p-Si Heterojunction Subjected to High Temperature Annealing for Electronics, MEMS, and LED Applications. Scientific reports, 7(1), 17734 (2017).

30. Sze, S. M.; Ng, K. K.: Physics of Semiconductor Devies; John Wiley \& Sons: New York, 2007.

31. Afanas' ev, V.V., Bassler, M., Pensl, G., Schulz, M.J. and Stein von Kamienski, E.: Band offsets and electronic structure of $\mathrm{SiC} / \mathrm{SiO} 2$ interfaces. Journal of Applied Physics, 79(6), 3108-3114 (1996).

32. Qamar, A., Dao, D. V., Tanner, P., Phan, H.-P., Dinh, T., Dimitrijev, S.: Influence of external mechanical stress on electrical properties of single-crystal n-3C-SiC/p-Si heterojunction diode. Applied Physics Express, 8(6), 061302 (2015).

33. Sethi, V. K., Pandey, M., Shukla, M. P.: Use of nanotechnology in solar PV cell. Int. Journal of Chemical Engineering and Applications, 2(2), 77-80 (2011).

34. Yang, Q., Guo, X., Wang, W., Zhang, Y., Xu, S., Lien, D.H., Wang, Z.L.: Enhancing sensitivity of a single $\mathrm{ZnO}$ micro-/nanowire photodetector by piezo-phototronic effect. ACS Nano, 4(10), 6285-6291 (2010).

35. Seyedi, M. A., Yao, M., O'Brien, J., Wang, S. Y., Dapkus, P. D.: Large area, low capacitance, GaAs nanowire photodetector with a transparent Schottky collecting junction. Applied Physics Letters, 103(25), 251109 (2013).

36. Dentan, M., de Cremoux, B.A.U.D.O.U.I.N.: Numerical simulation of the nonlinear response of a pin photodiode under high illumination. Journal of Lightwave Technology, 8(8), 1137-1144 (1990).

37. Li, Z., Pan, H., Chen, H., Beling, A., Campbell, J.C.: 2010. High-saturation-current modified uni-traveling-carrier photodiode with cliff layer. IEEE Journal of Quantum Electronics, 46(5), 626-632 (2010). 